Article

\title{
A New Fe $\mathrm{III}^{\mathrm{II}}$ Substituted Arsenotungstate $\left[\mathrm{Fe}^{\mathrm{III}}{ }_{2}\left(\mathrm{As}^{\mathrm{III}} \mathrm{W}_{6} \mathrm{O}_{23}\right)_{2}\left(\mathrm{As}^{\mathrm{III}} \mathrm{O}_{3} \mathrm{H}\right)_{2}\right]^{12-}$ : Synthesis, Structure, Characterization and Magnetic Properties
}

\author{
Masooma Ibrahim ${ }^{1, *} \mathbb{C}$, Yan Peng ${ }^{2}$ and Christopher E. Anson ${ }^{2}(\mathbb{C}$ \\ 1 Institute of Nanotechnology, Karlsruhe Institute of Technology, Hermann von-Helmholtz Platz 1, \\ 76344 Eggenstein-Leopoldshafen, Germany \\ 2 Institute of Inorganic Chemistry, Karlsruhe Institute of Technology, Engesserstrasse 15, \\ 76131 Karlsruhe, Germany; Py1688@yahoo.com (Y.P.); Christopher.Anson@kit.edu (C.E.A.) \\ * Correspondence: masooma.ibrahim@kit.edu
}

Received: 18 September 2020; Accepted: 19 October 2020; Published: 25 October 2020

check for updates

\begin{abstract}
The iron(III)-containing arsenotungstate $\left[\mathrm{Fe}^{\mathrm{III}}{ }_{2}\left(\mathrm{As}^{\mathrm{III}} \mathrm{W}_{6} \mathrm{O}_{23}\right)_{2}\left(\mathrm{As}^{\mathrm{III}} \mathrm{O}_{3} \mathrm{H}\right)_{2}\right]^{12-}$ (1) was prepared via a simple, one-pot reaction in aqueous basic medium. The compound was isolated as its sodium salt, and structurally-characterized by Single Crystal X-ray Diffraction (SCXRD), Powder X-ray Diffraction (PXRD), Fourier-Transform Infrared (FT-IR) spectroscopy, Thermogravimetric Analysis (TGA) and elemental analysis. Its magnetic properties are reported; the antiferromagnetic coupling between the two $\mathrm{Fe}^{\mathrm{III}}$ centers is unusually weak as a result of the bridging geometry imposed by the rigid arsenotungstate metalloligands.
\end{abstract}

Keywords: polyoxometalates; arsenotungstate; antiferromagnetism; iron; lacunary POMs

\section{Introduction}

Polyoxometalates (POMs) are discrete molecular metal oxides, typically composed of early transition metals (M) ( such as $\mathrm{W}^{6+}, \mathrm{Mo}^{6+}, \mathrm{V}^{5+}, \mathrm{Nb}^{5+}$ and $\mathrm{Ta}^{5+}$ ) in their high oxidation states. POMs have been attracting increasing interest in recent years owing to their enormous structural and compositional diversity and wide variety of applications [1-3]. The inherent properties of parent POMs can basically be modified by tuning the primary structural properties at the atomic or molecular level [4]. Lacunary (or vacant) POMs, which can be derived from parent polyanions of the Keggin $\left[\mathrm{XW}_{12} \mathrm{O}_{40}\right]^{\mathrm{n}-}$ or Wells-Dawson $\left[\mathrm{X}_{2} \mathrm{~W}_{18} \mathrm{O}_{61}\right]^{\mathrm{n}-}$ structures $\left(\mathrm{X}=\mathrm{Si}, \mathrm{Ge}, \mathrm{P}\right.$, As, etc.) by removal of one or more $\mathrm{W}^{\mathrm{VI}}$ centers under controlled basic conditions, are considered as multidentate all-inorganic ligands. POM ligands show a strong affinity to transition metal (TM) and lanthanide (Ln) cations, allowing the design and development of new POM-based materials with enhanced electronic properties [5-17]. A POM ligand with typical intrinsic properties, such as oxygen-rich surface, strong coordinating ability, various mode of coordination, adjustable/flexible size, thermal stability and hydrolytic stability, is expected to afford more rigid materials with a multitude of shapes, sizes and compositions in comparison with commonly utilized organic ligands [18]. More particularly, the bridging geometries imposed by POM-based ligands on di- or polynuclear metal complexes may differ significantly from those typically observed with the more usual organic-based bridging ligands, leading to different magnetic coupling scenarios. In addition, POMs may be promising inorganic diamagnetic ligands for constructing paramagnetic metal complexes, since the bulky feature of POM ligands assures an effective insulation of magnetic cores within the POM backbone, thus suppressing intermolecular magnetic interaction and polymerization [19-21]. Among magnetically functionalized POMs, the chemistry of iron-POMs is of great interest particularly for their inherent magnetic properties; they often exhibit interesting magnetic 
properties due to the high-spin $\mathrm{Fe}^{\mathrm{II} / \mathrm{III}}$ centers [22,23]. Another important aspect of iron-POMs is their catalytic applications due to the easily available $\mathrm{Fe}^{\mathrm{II} / \mathrm{III}}$ redox couple [24-27].

As part of our ongoing research on $\mathrm{Fe}(\mathrm{III})-\mathrm{POM}$ chemistry, we report here the dinuclear $\mathrm{Fe}^{\mathrm{III}}$-containing 12-tungsto-4-arsenite(III) $\left[\mathrm{Fe}^{\mathrm{III}}{ }_{2}\left(\mathrm{As}^{\mathrm{III}} \mathrm{W}_{6} \mathrm{O}_{23}\right)_{2}\left(\mathrm{As}^{\mathrm{III}} \mathrm{O}_{3} \mathrm{H}\right)_{2}\right]^{12-}(\mathbf{1})$, which has been synthesized under normal bench conditions by the reaction of $\mathrm{Na}_{2} \mathrm{WO}_{4} \cdot 2 \mathrm{H}_{2} \mathrm{O}, \mathrm{As}_{2} \mathrm{O}_{3}$ and $\mathrm{FeCl}_{3} \cdot 6 \mathrm{H}_{2} \mathrm{O}$ in basic medium, and characterized by single crystal X-ray crystallography (SCXD), powder X-ray diffraction (PXRD), Fourier-transform infrared (FT-IR) spectroscopy, elemental analysis and thermogravimetric analysis. The magnetic properties of 1 have been investigated.

\section{Experimental Section}

All reactions were carried out under aerobic conditions. All reagents were purchased commercially and were used without further purification.

\section{Synthesis}

Synthesis procedure for $\mathrm{Na}_{12}\left[\mathrm{Fe}^{\mathrm{III}}{ }_{2}\left(\mathrm{AsW}_{6} \mathrm{O}_{23}\right)_{2}\left(\mathrm{As}^{\mathrm{III}} \mathrm{O}_{3} \mathrm{H}\right)_{2}\right] \cdot 30 \mathrm{H}_{2} \mathrm{O}\{\mathbf{N a}-\mathbf{1}\}$.

A mixture of $\mathrm{Na}_{2} \mathrm{WO}_{4} \cdot 2 \mathrm{H}_{2} \mathrm{O}(4.20 \mathrm{~g}, 13.00 \mathrm{mmol}), \mathrm{As}_{2} \mathrm{O}_{3}(0.45 \mathrm{~g}, 2.27 \mathrm{mmol})$ and $\mathrm{FeCl}_{3} \cdot 6 \mathrm{H}_{2} \mathrm{O}$ $(0.33 \mathrm{~g}, 1.22 \mathrm{mmol})$ was dissolved in $50 \mathrm{~mL}$ of distilled water with stirring. The $\mathrm{pH}$ of the resultant suspension was adjusted to 8.5 and maintained at 8.5 by small addition of $\mathrm{Na}_{2} \mathrm{CO}_{3}(5 \mathrm{~g}, 4.71 \mathrm{mmol})$ and dropwise addition of $4 \mathrm{M} \mathrm{HCl}$. This solution was kept at $80{ }^{\circ} \mathrm{C}$ for two hours. After heating, the solution was filtered and $0.50 \mathrm{~mL}$ of $1 \mathrm{M}$ dimethylammonium chloride solution $\left(\mathrm{CH}_{3}\right)_{2} \mathrm{NH}_{2} \mathrm{Cl}$ was added to the clear filtrate. Slow evaporation of the clear solution led to light yellow crystals after approximately two weeks, which were isolated by filtration and dried in air. (Yield $350 \mathrm{mg}, \sim 13 \%$

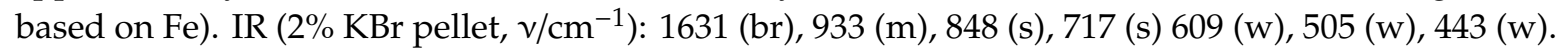
Elemental analysis (\%) calculated: W 51.69, As 7.02, Fe 2.62, Na 6.46; found: W 51.61, As 7.26, Fe 2.76, Na 6.32 .

\section{Results and Discussion}

\subsection{Synthesis}

The novel POM $\left[\mathrm{Fe}_{2}^{\mathrm{III}}{ }_{2}\left(\mathrm{As}^{\mathrm{III}} \mathrm{W}_{6} \mathrm{O}_{23}\right)_{2}\left(\mathrm{As}^{\mathrm{III}} \mathrm{O}_{3} \mathrm{H}\right)_{2}\right]^{12-}(\mathbf{1})$ was isolated as its sodium salt by reaction of $\mathrm{Fe}$ (III) ion with $\mathrm{Na}_{2} \mathrm{WO}_{4} \cdot 2 \mathrm{H}_{2} \mathrm{O}$ and $\mathrm{As}_{2} \mathrm{O}_{3}$ in the presence of $\left(\mathrm{Me}_{2} \mathrm{NH}_{2}\right) \mathrm{Cl}$ in basic medium ( $\mathrm{pH} 8$ ) at $80{ }^{\circ} \mathrm{C}$. Although dimethylammonium cations are not found in the crystal structure, their presence appears to play an important role in obtaining diffraction-quality crystals. The absence of the dimethylammonium cation was confirmed by elemental analyses, and no absorption bands for dimethylammonium cations were observed in the FT-IR spectrum of Na-I. In addition to delivering high-quality crystals, an organic cation was also a factor in obtaining a phase pure product. Whereas, the reactions which were carried out under the same conditions in absence of $\left(\mathrm{Me}_{2} \mathrm{NH}_{2}\right) \mathrm{Cl}$ produced a mixture of a yellow and white product. The investigation of this impure product by FT-IR spectroscopy indicates the presences of Na-1 and unidentified material (Figure S1).

\subsection{Single-Crystal X-ray Structure Determination}

The compound crystallizes as the hydrated sodium salt $\mathrm{Na}_{12}\left[\mathrm{Fe}^{\mathrm{III}}{ }_{2}\left(\mathrm{As}^{\mathrm{III}} \mathrm{W}_{6} \mathrm{O}_{23}\right)_{2}\left(\mathrm{As}^{\mathrm{III}} \mathrm{O}_{3} \mathrm{H}\right)_{2}\right] \cdot 30 \mathrm{H}_{2} \mathrm{O}$ $\{\mathbf{N a}-\mathbf{1}\}$ in the triclinic space group $P \overline{1}$ with $\mathrm{Z}=1$; the cluster thus has crystallographically-imposed inversion symmetry. Crystal data for $\mathbf{N a}-\mathbf{1}$ are summarized in Table 1 . The $\mathrm{X}$-ray structure of the anionic component $\left[\mathrm{Fe}^{\mathrm{III}} 2\left(\mathrm{AsW}_{6} \mathrm{O}_{23}\right)_{2}\left(\mathrm{As}^{\mathrm{III}} \mathrm{O}_{3} \mathrm{H}\right)_{2}\right]^{12-}(\mathbf{1})$ reveals that the two $\mathrm{Fe}^{\mathrm{III}}$ ions are sandwiched between two equivalent hexatungstate $\left\{\mathrm{As}_{2} \mathrm{~W}_{6}\right\}$ units (Figure 1). In $\left\{\mathrm{As}_{2} \mathrm{~W}_{6}\right\}$ moiety an arsenate group decorates the $\left\{\mathrm{AsW}_{6}\right\}$ units through two $\mu_{2}$-oxo bridges (via two As-O=W bridges). The highly vacant lacunary specie $\left\{\mathrm{As}_{2} \mathrm{~W}_{6}\right\}$ contains two edge-sharing tungstate triads $\left\{\mathrm{W}_{3} \mathrm{O}_{13}\right\}$ connected via their corner-sharing oxygen atoms (Figure 2 left). This type of building block and assembly are a common feature of most polytungstate clusters, but to the best of our knowledge a POM cluster based on two 
triads has been isolated for the first time in the present work. The hexalacunary unit $\left\{\mathrm{AsW}_{6}\right\}$ in $\mathbf{1}$ is different from the previously reported $\left\{\mathrm{PW}_{6}\right\}$ unit in structure $\left[\mathrm{P}_{8} \mathrm{~W}_{12} \mathrm{Co}_{2} \mathrm{Na}_{2} \mathrm{O}_{68}\right]^{18-}$ that contains three edge-sharing tungstate $\left\{\mathrm{W}_{2} \mathrm{O}_{10}\right\}$ units which connect to each other via their corner-sharing oxygen atoms, and a phosphate group then decorates each of these $\left\{\mathrm{W}_{2} \mathrm{O}_{10}\right\}$ units [28]. The hexalacunary $\left\{\mathrm{AsW}_{6}\right\}$ units are structurally related to the well-known trilacunary heteropolyanion $\left[\mathrm{B}-\mathrm{AsW}_{9} \mathrm{O}_{33}\right]^{9-}$ but with one missing triad $\left\{\mathrm{W}_{3} \mathrm{O}_{13}\right\}$. The two $\mathrm{Fe}^{\mathrm{III}}$ ions are bridged by two oxygen atoms from arsenite groups, $\mathrm{O}(1)$ and its inversion equivalent $\mathrm{O}\left(1^{\prime}\right)$. The rigid $\left\{\mathrm{As}_{2} \mathrm{~W}_{6}\right\}$ moieties impose a bridging geometry with a rather small Fe-O-Fe angle: $\mathrm{Fe}(1)-\mathrm{O}(1)=2.035(6) \AA, \mathrm{Fe}\left(1^{\prime}\right)-\mathrm{O}(1)=2.047(7) \AA, \mathrm{Fe}(1)-\mathrm{O}(1)-\mathrm{Fe}\left(1^{\prime}\right)=$ 99.1(3) ${ }^{\circ} \mathrm{Fe}(1)$ is six coordinate, adopting a distorted octahedral geometry (Figure 2 right), and this coordination sphere is completed by four oxido ligands from two $\left\{\mathrm{As}_{2} \mathrm{~W}_{6}\right\}$ units. Two protons are required for charge-balance, and these were located in the crystal structure, bonded to oxygens $\mathrm{O}(6)$ and $\mathrm{O}\left(6^{\prime}\right)$ of the outer arsenite moieties, where they are involved in hydrogen bonds to oxido ligands of neighboring cluster molecules (Figure 3). After submission of this work, it became apparent that the same compound is reported in the PhD thesis of Wenjing Liu, 2015, Jacobs University (Bremen, Germany), PhD mentor: Prof. U. Kortz. Also some other dinuclear tungstoarsenate(III) complexes $\left[\mathrm{H}_{2} \mathrm{M}_{2}\left(\mathrm{As}^{\mathrm{III}} \mathrm{W}_{6} \mathrm{O}_{23}\right)_{2}\left(\mathrm{As}^{\mathrm{III}} \mathrm{O}_{3}\right)_{2}\right]^{\mathrm{n}-}\left(\mathrm{M}=\mathrm{Sc} c^{\mathrm{III}}, \mathrm{In}^{\mathrm{III}}\right.$, and $\left.\mathrm{Ti}^{\mathrm{IV}}\right)$ and $\left[\mathrm{H}_{3} \mathrm{Cr}_{2}{ }^{\mathrm{III}}{ }_{2}\left(\mathrm{As}^{\mathrm{III}} \mathrm{W}_{6} \mathrm{O}_{23}\right)_{2}\left(\mathrm{As}^{\mathrm{III}} \mathrm{O}_{3}\right)_{2}\right]^{11-}$ have been reported there [29]. The polyanionic unit of these complexes also consist of two equivalent $\left\{\mathrm{As}_{2} \mathrm{~W}_{6}\right\}$ units, which then sandwich two metal ions bridged by four $\mathrm{M}-\mathrm{O}-\mathrm{W}$ and two $\mathrm{M}-\mathrm{O}-\mathrm{As}$ bridges. These central embedded metal ions also adopt a distorted octahedral geometry similar to $\mathrm{Fe}^{\mathrm{III}}$ metal ion geometry in $\mathbf{1}$.

Table 1. Crystal Data.

\begin{tabular}{cc}
\hline Compound & $\mathrm{Na}-\mathbf{1}$ \\
\hline Formula & $\mathrm{As}_{4} \mathrm{H}_{90} \mathrm{Fe}_{2} \mathrm{Na}_{12} \mathrm{O}_{96}$ \\
Formula weight & 4520.17 \\
Crystal System & Triclinic \\
Space Group & $\mathrm{P} \overline{1}$ \\
$a / \AA$ & $11.9906(9)$ \\
$b / \AA$ & $13.1591(9)$ \\
$c / \AA$ & $15.0490(9)$ \\
$\alpha /^{\circ}$ & $88.242(5)$ \\
$\beta /{ }^{\circ}$ & $89.361(6)$ \\
$\gamma /{ }^{\circ}$ & $74.518(5)$ \\
$U / \AA^{3}$ & $2287.3(3)$ \\
$Z$ & 1 \\
$\mathrm{~T} / \mathrm{K}$ & $150(2)$ \\
$F(000)$ & 2062 \\
$D_{c} / \mathrm{Mg} \mathrm{m}^{-3}$ & 3.282 \\
$\mu(\mathrm{Ga}-\mathrm{K} \alpha) / \mathrm{mm}^{-1}$ & 23.123 \\
Data Measured & 21,626 \\
Unique Data & 9508 \\
$R_{\text {int }}$ & 0.0378 \\
Data with I $\geq 2 \sigma(\mathrm{I})$ & 9017 \\
$w R_{2}($ all data $)$ & 0.1663 \\
$S($ all data $)$ & 1.056 \\
$R_{1}[\mathrm{I} \geq 2 \sigma(\mathrm{I})]$ & 0.0578 \\
Parameters/Restraints & $598 / 1$ \\
Biggest diff. peak/hole/e $\AA^{-3}$ & $2.46 /-3.14$ \\
$\mathrm{CSD}$ number & $2,022,893$ \\
\hline &
\end{tabular}




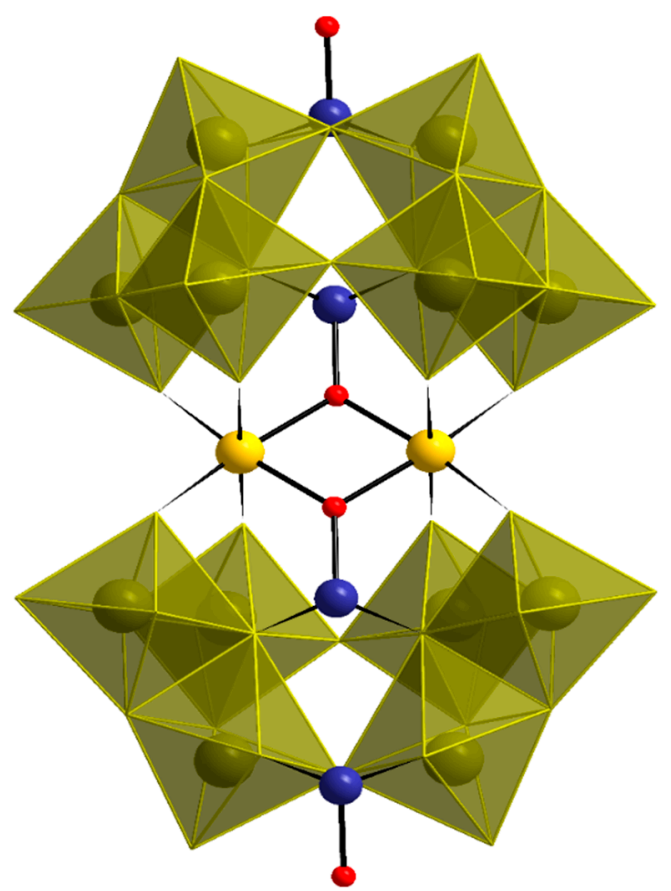

Figure 1. Combined polyhedral/ball-and-stick representation of $\mathbf{1}$. Color code: $\mathrm{WO}_{6}$ octahedra olive green, As blue, Fe yellow, O red.

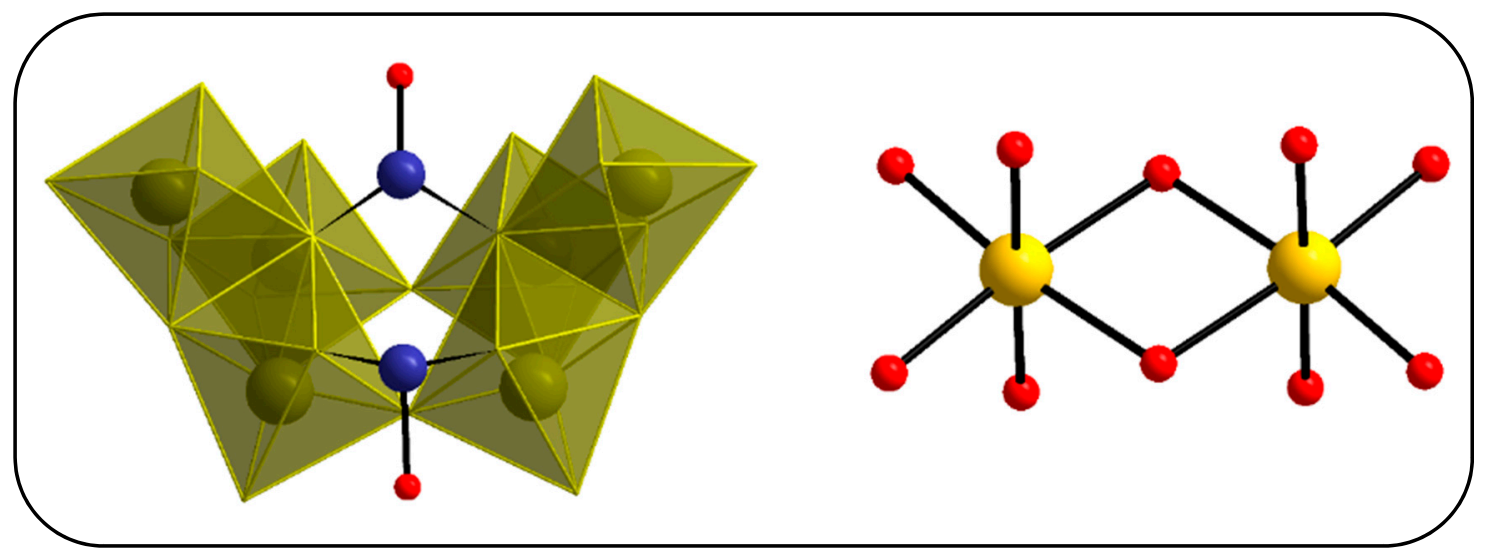

Figure 2. Combined polyhedral/ball-and-stick representation: Left $\left\{\left(\mathrm{As}^{\mathrm{III}} \mathrm{W}_{6} \mathrm{O}_{23}\right)\left(\mathrm{As}^{\mathrm{III}} \mathrm{O}_{3} \mathrm{H}\right)\right\}$. Right $\mathrm{Fe}^{\mathrm{III}} 2$ core. Color code: $\mathrm{WO}_{6}$ octahedra olive green, As blue, Fe yellow, $\mathrm{O}$ red. 


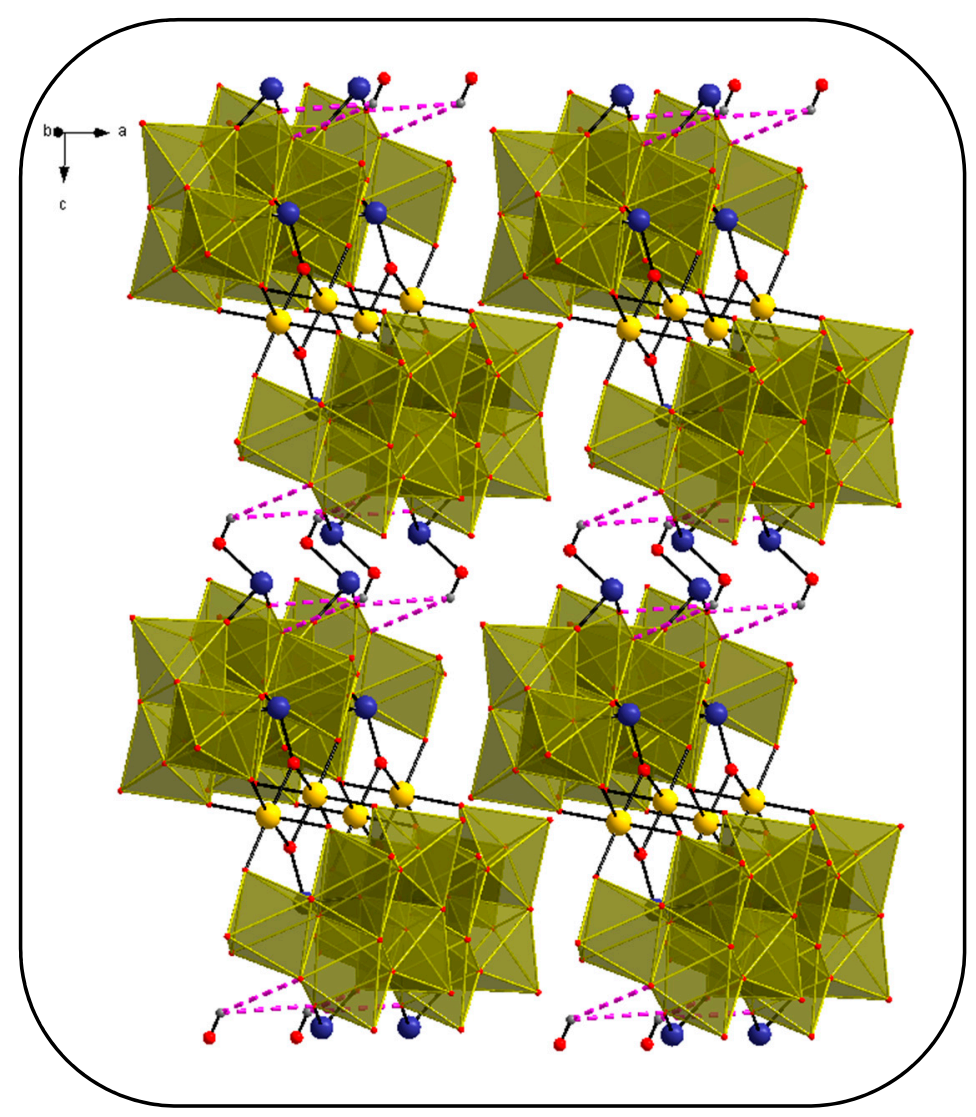

Figure 3. The packing arrangements in 1. Hydrogen bonds are drawn as pink dashed lines. Color code: $\mathrm{WO}_{6}$ octahedra olive green, As blue, Fe yellow, $\mathrm{O}$ red, $\mathrm{H}$ gray.

\subsection{Characterizations}

The experimental powder XRD pattern (measured at room temperature) is compatible with the pattern simulated from the solved crystal structure are shown in Figure 4. The diffraction peaks of both calculated and experimental patterns match well, which indicates the phase purity of the bulk product.

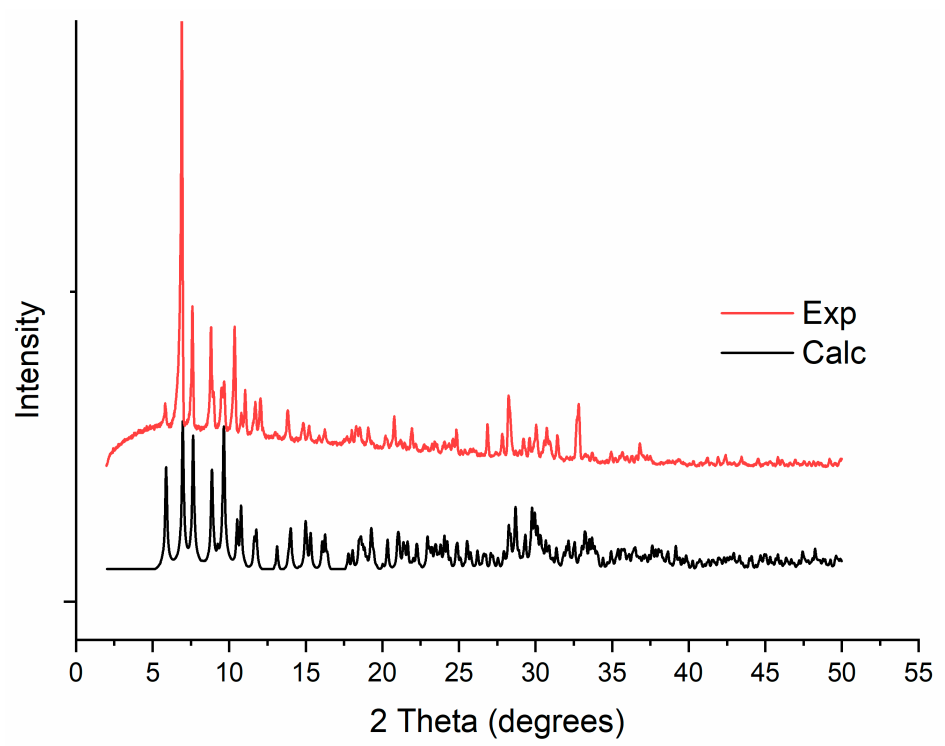

Figure 4. Experimental (red) and simulated (black) X-ray diffraction pattern of Na-1. 


\subsubsection{Vibrational Spectroscopy}

The FT-IR spectrum of Na-1 displays a fingerprint region that is characteristic of tungstoarsenates [30]. The observed bands at $933 \mathrm{~cm}^{-1}$ and $848 \mathrm{~cm}^{-1}$ are assigned to $v_{\text {as }}\left(\mathrm{W}=\mathrm{O}_{\mathrm{t}}\right)$, and $v_{\mathrm{as}}\left(\mathrm{W}-\mathrm{O}_{\mathrm{b}}-\mathrm{W}\right)$ vibrations, respectively. The bands belonging to $\mathrm{W}-\mathrm{O}_{\mathrm{c}}-\mathrm{W}$ vibrations appeared at 717 and $609 \mathrm{~cm}^{-1}$. The absorption bands of the As-O $\left(900 \mathrm{~cm}^{-1}\right)$ vibrations are partially overlapped with the $v_{\mathrm{as}}\left(\mathrm{W}-\mathrm{O}_{\mathrm{b}}-\mathrm{W}\right)$ ones. The strong peak at about $1630 \mathrm{~cm}^{-1}$ corresponds to vibrations of lattice water molecules. No vibrational modes of dimethylammonium cations were observed (Figure S1).

\subsubsection{Thermogravimetric Analysis}

The thermal decomposition processes for Na-1 was investigated under an $\mathrm{N}_{2}$ atmosphere from room temperature (RT) to $1000^{\circ} \mathrm{C}$ (Figure S2). The TGA curve indicates two weight loss steps. The first step corresponds to the dehydration process, which starts at RT and is completed at around $\sim 340^{\circ} \mathrm{C}$. This weight loss involves the loss of 25 water molecules [\% calc. (found): 12.6 (11)]. The second weight loss occurs between $340^{\circ} \mathrm{C}$ and $587^{\circ} \mathrm{C}$ which can be associated to the removal of two arsenic groups $\{\mathrm{AsO}\}$ per formula unit [\% calc. (found): 4.8 (4.0)]. The slight difference between the calculated and observed values for water content observed in TGA of Na-1 can be justified by a higher degree of dryness of the sample used for TGA analysis. The final residue $\mathrm{Na}_{12} \mathrm{As}_{2} \mathrm{Fe}_{2} \mathrm{~W}_{12} \mathrm{O}_{50}(\sim 83 \%$ (calc.) remained stable between $587^{\circ} \mathrm{C}$ and $1000{ }^{\circ} \mathrm{C}$ and accounts for $85 \%$ (found) of the total mass.

\subsection{Magnetic Properties}

Variable-temperature magnetic susceptibility studies were carried out on powder samples in the temperature range 2 to $300 \mathrm{~K}$ and in an applied field of 1000 Oe (Figure S3). As shown in Figure 5, the $\chi \mathrm{T}$ product is $8.45 \mathrm{~cm}^{3} \mathrm{~K} \mathrm{~mol}^{-1}$ at $300 \mathrm{~K}$, which is good agreement with the expected value of $8.75 \mathrm{~cm}^{3} \mathrm{~K} \mathrm{~mol}^{-1}$ for a dinuclear species containing two non-interacting $\mathrm{Fe} \mathrm{e}^{\mathrm{III}}(S=5 / 2)$ ions. Upon cooling, the $\chi \mathrm{T}$ values decrease slowly between 300 and $50 \mathrm{~K}$ and quickly between 50 and $2 \mathrm{~K}$, reaching a minimum value of $0.64 \mathrm{~cm}^{3} \mathrm{~K} \mathrm{~mol}^{-1}$ at $2 \mathrm{~K}$, indicating the presence of a weak antiferromagnetic exchange interaction between the $\mathrm{Fe}^{\mathrm{III}}$ ions. The field dependence of the magnetization of Na-1 was measured over the range 0 to $7 \mathrm{~T}$ at 2, 4 and $5 \mathrm{~K}$ (Figure 6), and shows typical behavior for an antiferromagnetically coupled $\left\{\mathrm{Fe}^{\mathrm{III}}{ }_{2}\right\}$ system. The $\chi \mathrm{T}$ vs. $\mathrm{T}$ and $\mathrm{M}$ vs. $\mathrm{H}$ plots could be fitted with a $\mathrm{H}=-2 J\left(\mathbf{S}_{\mathbf{1}} . \mathbf{S}_{2}\right)$ Hamiltonian using PHI [31], giving best-fit parameters $J_{F e-F e}=-1.0 \mathrm{~K}$ and $g=2.0$. Such a coupling is unusually weak for a bis-oxygen-bridged dinuclear $\mathrm{Fe}^{\mathrm{III}}{ }_{2}$ complex, being nearly as weak as that $(-0.33 \mathrm{~K})$ previously reported by some of us in a Fe ${ }^{\mathrm{III}}{ }_{2} \mathrm{Y}_{2}$ butterfly complex [32], and results from the bridging geometry between the iron centers imposed by the two rigid $\mathrm{W}_{6} \mathrm{As}_{2}$ metalloligands. The most widely used magnetostructural correlation for bridged $\mathrm{Fe}^{\mathrm{III}}$ systems has been that proposed by Christou and co-workers in 2004 [33], which gives J(calc) $=-7.0 \mathrm{~K}$ for Na-1. They more recently proposed a modified correlation [34], but this gives a very similar J(calc) (-6.7 K) for Na-1. Some of us have previously shown that the coupling constants calculated from the earlier correlation are typically 5-6 K too antiferromagnetic [x4], and if this correction is applied then the calculated value, from either version of the correlation, falls well into line with the experimental value found here. This confirms that, provided our correction is applied, both the correlations are also valid for systems with very weak interactions, such as the present complex, by the two rigid $\left\{\mathrm{As}_{2} \mathrm{~W}_{6}\right\}$ metalloligands. The most widely used magnetostructural correlation for bridged $\mathrm{Fe}^{\mathrm{III}}$ systems, that proposed by Canada-Viltalta et al. [33], gives $J($ calc $)=-6.9 \mathrm{~K}$. We have previously shown that values calculated from this correlation are typically 5-6 K too antiferromagnetic [35], and if this correction is applied then the calculated value falls well into line with the experiment, confirming that this correlation is still valid even for systems with very weak interactions, such as the present complex. 


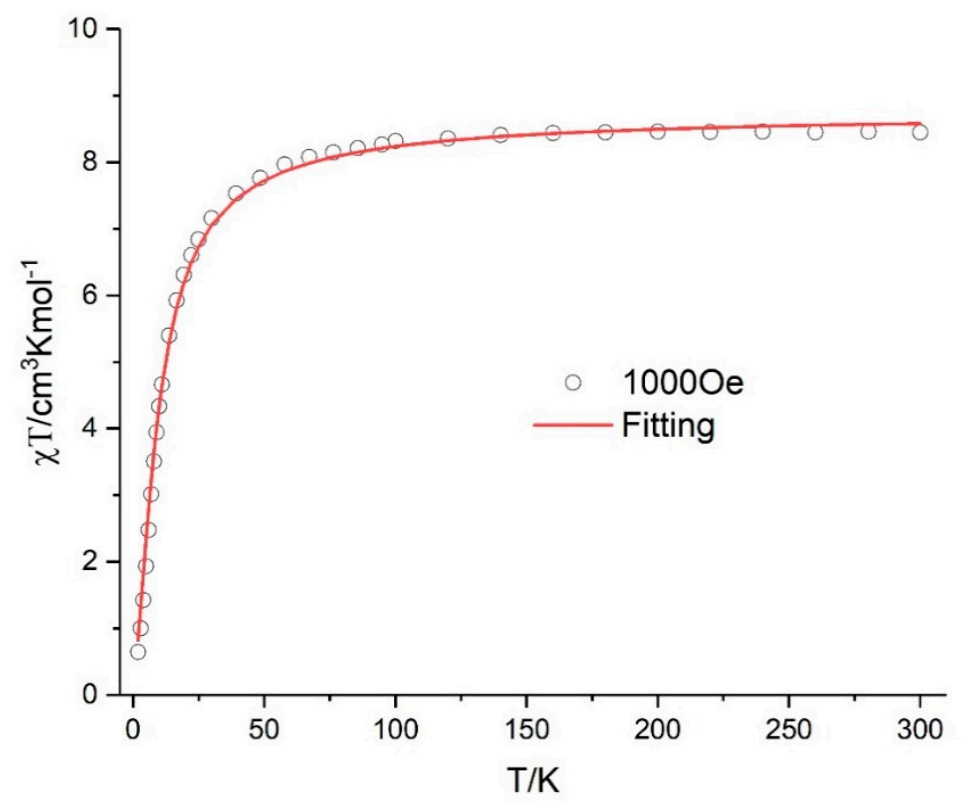

Figure 5. Plot of $\chi \mathrm{T}$ vs. T for Na-1 under 1000 Oe applied dc field. Solid line for fitting.

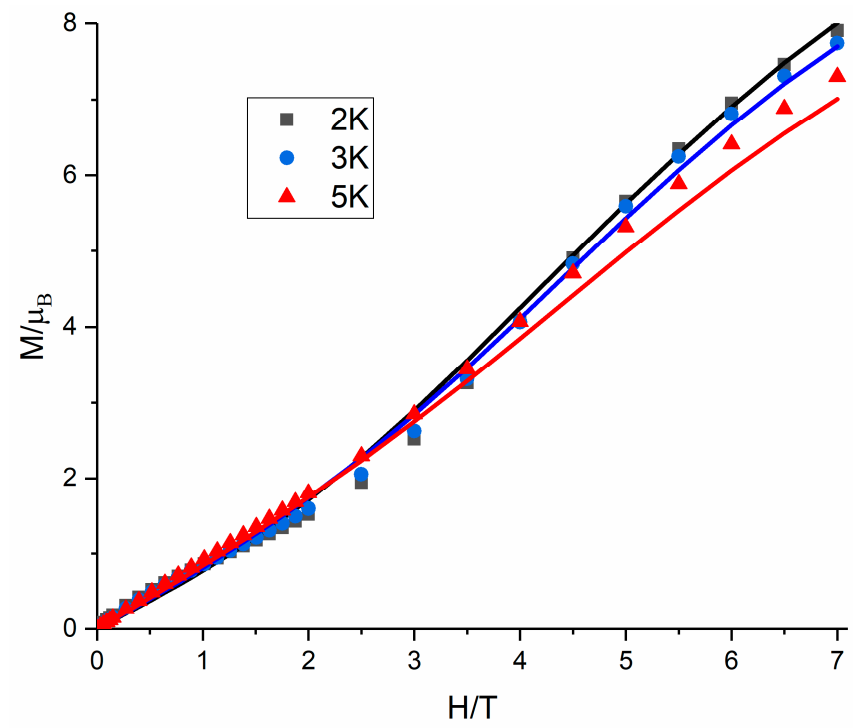

Figure 6. Plot of M vs. $\mathrm{H}$ for Na-1 at 2, 3 and $5 \mathrm{~K}$. Solid lines for fitting.

\section{Conclusions}

We have prepared and structurally characterized the first $\mathrm{Fe}^{\mathrm{III}}$-containing hexalacunary heteroarsenotungstate 1 by using simple open-beaker, aqueous solution synthesis technique. The new heteropolyanion architecture involves the sandwiching of the two paramagnetic iron centers between two rigid $\left\{\mathrm{As}_{2} \mathrm{~W}_{6}\right\}$ metalloligands, and the geometry imposed by these on the $\mathrm{Fe}^{\mathrm{III}}{ }_{2}$ core resulted in an unusually weak antiferromagnetic interaction. Future work will be concentrated on exploring the hexalacunary systems with variety of paramagnetic and diamagnetic cations with related magnetic and catalytic investigations.

Supplementary Materials: The following are available online at http://www.mdpi.com/2312-7481/6/4/54/s1, Figure S1: FT-IR spectra of pure Na-1 (black) and mixture of product obtained in absence of $\left(\mathrm{Me}_{2} \mathrm{NH}_{2}\right)^{+}$cation (red), Figure S2: Thermogravimetric analysis (TGA) curve of Na-1, Figure S3: Plot of chiT vs. T under 1000 Oe for compound Na-1.

Author Contributions: All the authors contributed to this work. M.I. conceived and designed the experiments. M.I. characterized the compound. Structure refinement was done by C.E.A. Magnetic data were processed by Y.P. 
The manuscript was written with participation of all authors, who have all checked and approved the manuscript. All authors have read and agreed to the published version of the manuscript.

Funding: German Science Foundation (DFG. Grant Number: 123/1-1).

Acknowledgments: M.I. acknowledges support by the Helmholtz society through program Science and Technology of Nanosystems (STN). We also thank Dieter Fenske and Thomas Bergfeldt for measuring the single crystal X-ray crystallography dataset and the elemental analysis respectively. We thank Valeriu Mereacre for the magnetic measurements. COST Actions MultiComp (CA15107) and MOLSPIN (CA15128), KNMF and POF.

Conflicts of Interest: The authors declare no conflict of interest.

\section{References}

1. Anyushin, A.V.; Kondinski, A.; Parac-Vogt, T.N. Hybrid polyoxometalates as post-functionalization platforms: From fundamentals to emerging applications. Chem. Soc. Rev. 2020, 49, 382-432. [CrossRef] [PubMed]

2. Sullivan, K.P.; Yin, Q.; Collins-Wildman, D.L.; Tao, M.; Geletii, Y.V.; Musaev, D.G.; Lian, T.; Hill, C.L. Multitasking POM systems. Front. Chem. 2018, 6, 365. [CrossRef] [PubMed]

3. Long, D.L.; Tsunashima, R.; Cronin, L. Polyoxometalates: Building blocks for functional nanoscale systems. Angew. Chem. Int. Ed. 2010, 49, 1736-1758. [CrossRef] [PubMed]

4. Stuckart, M.; Monakhov, K.Y. Polyoxometalates as components of supramolecular assemblies. Chem. Sci. 2019, 10, 4364-4376. [CrossRef]

5. Oms, O.; Dolbecq, A.; Mialane, P. Diversity in structures and properties of 3d-incorporating polyoxotungstates. Chem. Soc. Rev. 2012, 41, 7497-7536. [CrossRef]

6. Reinoso, S. Heterometallic 3d-4f polyoxometalates: Still an incipient field. Dalton Trans. 2011, 40, 6610-6615. [CrossRef]

7. Boskovic, C. Rare earth polyoxometalates. Acc. Chem. Res. 2017, 50, 2205-2214. [CrossRef]

8. Zhao, J.W.; Li, Y.Z.; Chen, L.J.; Yang, G.Y. Research progress on polyoxometalate-based transition-metal-rareearth heterometallic derived materials: Synthetic strategies, structural overview and functional applications. Chem. Commun. 2016, 52, 4418-4445. [CrossRef]

9. Ibrahim, M.; Mereacre, V.; Leblanc, N.; Wernsdorfer, W.; Anson, C.E.; Powell, A.K. Self-assembly of a giant tetrahedral $3 \mathrm{~d}-4 \mathrm{f}$ single-molecule magnet within a polyoxometalate system. Angew. Chem. Int. Ed. 2015, 54, 15574-15578. [CrossRef]

10. Ibrahim, M.; Lan, Y.; Bassil, B.S.; Xiang, Y.; Suchopar, A.; Powell, A.K.; Kortz, U. Hexadecacobalt(II)-containing polyoxometalate-based single-molecule magnet. Angew. Chem. Int. Ed. 2011, 50, 4708-4711. [CrossRef]

11. AlDamen, M.A.; Clemente-Juan, J.M.; Coronado, E.; Martí-Gastaldo, C.; Gaita-Arino, A. Mononuclear lanthanide single-molecule magnets based on polyoxometalates. J. Am. Chem. Soc. 2008, 130, 8874-8875. [CrossRef]

12. Ritchie, C.; Ferguson, A.; Nojiri, H.; Miras, H.N.; Song, Y.F.; Long, D.L.; Burkholder, E.; Murrie, M.; Kögerler, P.; Brechin, E.K.; et al. Polyoxometalate-mediated self-assembly of single-molecule magnets: $\left\{\left[\mathrm{XW}_{9} \mathrm{O}_{34}\right]_{2}\left[\mathrm{Mn}^{\mathrm{III}}{ }_{4} \mathrm{Mn}_{2}{ }_{2} \mathrm{O}_{4}\left(\mathrm{H}_{2} \mathrm{O}\right)_{4}\right]\right\}^{12-}$. Angew. Chem Int. Ed. 2008, 47, 5609-5612. [CrossRef] [PubMed]

13. Feng, X.; Zhou, W.; Li, Y.; Ke, H.; Tang, J.; Clérac, R.; Wang, Y.; Su, Z.; Wang, E. Polyoxometalate-supported 3d-4f heterometallic single-molecule magnets. Inorg. Chem. 2012, 51, 2722-2724. [CrossRef]

14. Izarova, N.V.; Kögerler, P. Polyoxometalate-based single-molecule magnets. In Trends in Polyoxometalates Research; Ruhlmann, L., Schaming, D., Eds.; Nova Science Publishers: Hauppauge, NY, USA, 2015; pp. 121-149.

15. El Moll, H.; Dolbecq, A.; Marrot, J.; Rousseau, G.; Haouas, M.; Taulelle, F.; Rogez, G.; Wernsdorfer, W.; Keita, B.; Mialane, P. A stable hybrid bisphosphonate polyoxometalate single-molecule magnet. Chem. Eur. J. 2012, 18, 3845-3849. [CrossRef]

16. Li, Z.; Li, X.X.; Yang, T.; Cai, Z.W.; Zheng, S.T. Four-shell polyoxometalates featuring high-nuclearity $\mathrm{Ln}_{26}$ Clusters: Structural transformations of nanoclusters into frameworks triggered by transition-metal ions. Angew. Chem. Int. Ed. 2017, 56, 2664-2669. [CrossRef] [PubMed]

17. Ritchie, C.; Moore, E.G.; Speldrich, M.; Kögerler, P.; Boskovic, C. Terbium polyoxometalate organic complexes: Correlation of structure with luminescence properties. Angew. Chem. Int. Ed. 2010, 49, 7702-7705. [CrossRef]

18. Katsoulis, D.E. A survey of applications of polyoxometalates. Chem. Rev. 1998, 98, 359-388. [CrossRef] [PubMed] 
19. Clemente-Juan, J.M.; Coronado, E.; Gaita-Ariño, A. Magnetic polyoxometalates: From molecular magnetism to molecular spintronics and quantum computing. Chem. Soc. Rev. 2012, 41, 7464-7478. [CrossRef]

20. Coronado, E.; Gómez-García, C.J. Polyoxometalate-based molecular materials. Chem. Rev. 1998, 98, $273-296$. [CrossRef]

21. Vonci, M.; Boskovic, C. Polyoxometalate-supported lanthanoid single-molecule magnets. Aust. J. Chem. 2014, 67, 1542-1552. [CrossRef]

22. Compain, J.D.; Mialane, P.; Dolbecq, A.; Mbomekallé, I.M.; Marrot, J.; Sécheresse, F.; Riviére, E.; Rogez, G.; Wernsdorfer, W. Iron polyoxometalate single-molecule magnets. Angew. Chem. Int. Ed. 2009, 48, 3077-3081. [CrossRef] [PubMed]

23. Pichon, C.; Dolbecq, A.; Mialane, P.; Marrot, J.; Rivière, E.; Sécheresse, F. Square versus tetrahedral iron clusters with polyoxometalate ligands. J. Chem. Soc. Dalton Trans. 2007, 707, 71-76. [CrossRef] [PubMed]

24. Ibrahim, M.; Haider, A.; Xiang, Y.; Bassil, B.S.; Carey, A.M.; Rullik, L.; Jameson, G.B.; Doungmene, F.; Mbomekallé, I.M.; de Oliveira, P.; et al. Tetradecanuclear iron(III)-oxo nanoclusters stabilized by trilacunary heteropolyanions. Inorg. Chem. 2015, 54, 6136-6146. [CrossRef] [PubMed]

25. Singh, V.; Chen, Z.; Ma, P.; Zhang, D.; Drew, M.G.B.; Niu, J.; Wang, J. Unprecedented $\left\{\mathrm{Fe}_{14}\right\} /\left\{\mathrm{Fe}_{10}\right\}$ Polyoxotungstate-based nanoclusters with efficient photocatalytic $\mathrm{H}_{2}$ evolution activity: Synthesis, structure, magnetism, and electrochemistry. Chem. Eur. J. 2016, 22, 10983-10989. [CrossRef]

26. Botar, B.; Geletii, Y.V.; Kögerler, P.; Musaev, D.G.; Morokuma, K.; Weinstock, I.A.; Hill, C.L. The true nature of the di-iron(III) $\gamma$-Keggin structure in water: Catalytic aerobic oxidation and chemistry of an unsymmetrical trimer. J. Am. Chem. Soc. 2006, 128, 11268-11277. [CrossRef]

27. Du, X.; Ding, Y.; Song, F.; Ma, B.; Zhao, J.; Song, J. Efficient photocatalytic water oxidation catalyzed by polyoxometalate $\left[\mathrm{Fe}_{11}\left(\mathrm{H}_{2} \mathrm{O}\right)_{14}(\mathrm{OH})_{2}\left(\mathrm{~W}_{3} \mathrm{O}_{10}\right)_{2}\left(\alpha-\mathrm{SbW}_{9} \mathrm{O}_{33}\right)_{6}\right]^{27-}$ based on abundant metals. Chem. Commun. 2015, 51, 13925-13928. [CrossRef]

28. Ritchie, C.; Li, F.; Pradeep, C.P.; Long, D.L.; Xu, L.; Cronin, L. A functional hybrid polyoxometalate framework based on a 'trilacunary' heteropolyanion $\left[\left(\mathrm{P}_{4} \mathrm{~W}_{6} \mathrm{O}_{34}\right)_{2} \mathrm{Co}_{2} \mathrm{Na}_{2}\left(\mathrm{H}_{2} \mathrm{O}\right)_{2}\right]^{18-}$. J. Chem. Soc. Dalton Trans. 2009, 2, 6483-6486. [CrossRef]

29. Wenjing, L. Synthesis of Chromium-Containing and Some other Heteropolytungstates and Study of Their Magnetic, Electrochemical, and Biological Properties. Ph.D. Thesis, Jacobs University Bremen, Bremen, Germany, 2015.

30. Detusheva, L.G.; Kuznetsova, L.I.; Dovlitova, L.S.; Likholobov, V.A. Study of the equilibrium of formation of arsenic(III) lacunar heteropolytungstates by Raman spectroscopy. Russ. Chem. Bull. 2003, 52, 370-374. [CrossRef]

31. Chilton, N.F.; Anderson, R.P.; Turner, L.D.; Soncini, A.; Murray, K.S. PHI: A powerful new program for the analysis of anisotropic monomeric and exchange-coupled polynuclear d- and f-block complexes. J. Comput. Chem. 2013, 34, 1164-1175. [CrossRef]

32. Xiang, H.; Mereacre, V.; Lan, Y.; Lu, T.-B.; Anson, C.E.; Powell, A.K. Direct observation of the role of lanthanides in stabilizing a ferromagnetic spin orientation in a weak $\mathrm{Fe}^{\mathrm{III}}-\mathrm{Fe}^{\mathrm{III}}$ antiferromagnet. Chem. Commun. 2013, 49, 7385-7387. [CrossRef]

33. Canada-Vilalta, C.; O’Brien, T.A.; Brechin, E.K.; Pink, M.; Davidson, E.R.; Christou, G. Large spin differences in structurally related $\mathrm{Fe}_{6}$ molecular clusters and their magnetostructural explanation. Inorg. Chem. 2004, 43, 5505-5521. [CrossRef] [PubMed]

34. Mitchell, K.J.; Abboud, K.A.; Christou, G. Magnetostructural correlation for high-nuclearity iron(III)/oxo complexes and application to $\mathrm{Fe}_{5}, \mathrm{Fe}_{6}$, and $\mathrm{Fe}_{8}$ clusters. Inorg. Chem. 2016, 55, 6597-6608. [CrossRef]

35. Ako, A.M.; Lan, Y.; Mereacre, V.; Ruiz, E.; Aravena, D.; Anson, C.E.; Powell, A.K. Spins on a curved surface: A Fe ${ }_{14}{ }_{14}$ ferracalixarene. Dalton Trans. 2013, 42, 9606-9612. [CrossRef] [PubMed]

Publisher's Note: MDPI stays neutral with regard to jurisdictional claims in published maps and institutional affiliations. 